\title{
Potassium Urine Excretion Rate
}

National Cancer Institute

\section{Source}

National Cancer Institute. Potassium Urine Excretion Rate. NCI Thesaurus. Code C117839.

A determination of the amount of potassium being excreted in urine over a defined period of time. 